\title{
Effects of revision of Japanese food composition tables on estimation of nutrient intakes, with reference to age-dependent differences
}

\author{
Naoko Matsuda-Inoguchi ${ }^{1}$, Shinichiro Shimbo ${ }^{1}$, Haruo Nakatsuka ${ }^{2}$, Takao Watanabe ${ }^{3}$, \\ Kae Higashikawa ${ }^{4}$ and Masayuki lkeda ${ }^{4, *}$ \\ ${ }^{1}$ Department of Food and Nutrition, Kyoto Women's University, Kyoto, Japan: ${ }^{2}$ Miyagi University, Taiwa-cho, Japan: \\ ${ }^{3}$ Miyagi University of Education, Sendai, Japan: ${ }^{4}$ Kyoto Industrial Health Association, 67 Nishinokyo-Kitatsuboicho, \\ Nakagyo-ku, Kyoto 604-8472, Japan
}

Submitted 1 October 2003: Accepted 3 February 2004

\begin{abstract}
Objective: To identify effects of revision of the Japanese food composition tables from the fourth version to the fifth version on nutrient intake estimation.

Design: A database on 783 samples of 24-hour food duplicate portions was re-visited. Nutrients in the duplicate portions were estimated by use of the fourth and fifth versions of the Japanese food composition tables in parallel, together with supplemental use of other databases. The two sets of estimates were subjected to comparison.

Setting: The sample collection was conducted at 31 sites all over Japan.

Subjects: The sample donors were 783 women aged $20-78$ years.

Results: Compared with the estimates by use of the fourth version of the tables, the estimates by the fifth version were substantially higher for intakes of energy, carbohydrate, dietary fibre, vitamin A and niacin, and lower for iron intake. The increase in carbohydrate intake estimates was more evident in older women than in young women, whereas the decrease in the intake estimation of iron and the increase in that of dietary fibre were more marked in young women than in older women. Conclusion: The recent revision of food composition tables in Japan induced substantial changes in the estimation of nutrient intakes, i.e. an increase in energy, carbohydrate, dietary fibre, vitamin A and niacin, and a decrease in iron. The extent of the changes varied depending on age.
\end{abstract}

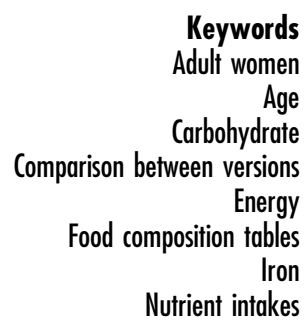

Adequate intake of nutrients is one of the essentials for healthy life. For the estimation of nutrient intakes, food composition tables are an important tool having wide application in both clinical and public health practice ${ }^{1}$. In addition, food composition tables are often a common tool when several methods of nutrient intake estimation are compared $^{2-6}$. As the tables should be reliable in estimating nutrient intakes, the tables themselves are also subject to validation studies ${ }^{7-9}$.

In Japan, the food composition tables were revised recently to produce the fifth version of the tables ${ }^{10}$ almost 20 years after publication of the previous version (the fourth version ${ }^{11}$ ) in 1982. Revision of the tables has been practised several times in the history of the National Nutritional Survey ${ }^{12,13}$ in Japan: the first version of the food composition tables was used from 1948 to 1954, the second version from 1955 to 1963 , and the third version from 1964 to 1970. After a period of atypical use of categorised food group tables, the fourth version with several supplemental publications enjoyed a long period of application from 1988 to 2001. Regardless of these changes in the tables used, the differences between the estimates by the incoming new version and those by the previous version of the tables were generally small, i.e. less than $4 \%{ }^{14}$

The latest (i.e. fifth) version ${ }^{10}$ covers more food items (1882 items, compared with 1621 items in the fourth version $^{11}$ ) with more detailed classification. It was thought possible, therefore, that the revision might influence the estimation of nutrient intakes. Accordingly, this group conducted a pilot study on 71 girl students to compare their nutrient intakes as estimated by use of the fourth version of the food composition tables with that estimated by the fifth version. The study indicated that estimation by use of the fifth version gave increases in energy (7\%), carbohydrate (8\%) and vitamin A (20\%) intakes, and a decrease in iron intake $(-13 \%)^{14}$.

It is known, however, that the food habits of girl students may be biased and not typical of those 
of women ${ }^{15-19}$. The present analyses were initiated, therefore, to examine if the conclusions obtained in that study of girl students are applicable also to women in general, by expanding the study population both in number and age range of the subjects.

\section{Methods}

\section{Study population}

In 1991 to 1998,783 adult women at 31 sites in eight regions of Japan (for locations, see Fig. 1) offered food duplicate portion samples on a voluntary basis ${ }^{14,20}$. The duplicate portion database thus established ${ }^{14,20}$ was re-visited for the present analysis. The ages of the participants (mostly housewives, except for young women) were distributed over a wide range from 20 to 78 years, with a mean \pm standard deviation (SD) of $49.8 \pm 12.8$ years. The majority of women were in their 50 s (264 cases), followed by those in their 40 s (198 cases) and women their 60s (157 cases) ${ }^{20}$.

\section{Collection of food duplicate portion samples}

Each participant provided her informed consent. She was carefully instructed to cook an ordinary everyday meal (i.e. no special dishes) ${ }^{14}$. Subsequently, she offered 24hour food duplicate portion samples ${ }^{21}$ together with food menus (the names of each dish) of the day. The procedures for recording the food items have been described previously in detail ${ }^{14}$; in short, each food item in the sample was separated manually under supervision of a veteran nutritionist, and the weight of each food item was recorded with reference to the menu.

\section{Estimation of nutrient intakes}

For the fourth version-based estimation of daily nutrient intakes, the nutritionist coded all items by use of the fourth version of the standard tables of food composition ${ }^{11}$, the standard tables of dietary fibre ${ }^{22}$, the standard tables of fatty acids, cholesterol and vitamin $\mathrm{E}^{23}$, and the food composition tables on commercial pre-cooked foods ${ }^{24}$, in combination. In the case that a code for a food item of concern was not listed in the tables, an available item of close botanical or zoological relevance was taken as a surrogate ${ }^{25}$. Nutrient intake was first estimated from the food weight record and the code number for each food item, and the estimates were then summed up for daily intake on an individual basis as well as on a group basis.

In the next step, to make the fifth version-based estimation of daily nutrient intakes, the same nutritionist coded all items again, but with reference to the fifth version of the tables ${ }^{10}$ (as amended after corrections given on the Resources Council home page on 28 March 2001), together with the food composition tables on commercial precooked foods ${ }^{24}$. Although more food codes were available in the fifth version of the tables as described above, use of the pre-cooked food tables ${ }^{24}$ still remained necessary.

\section{Data analysis}

Comparisons were made for energy, three macronutrients (including carbohydrate), dietary fibre, five minerals, five vitamins, fatty acids and cholesterol, as listed in Table 1. A normal distribution was assumed for all nutrient intakes, so that the distribution was expressed as mean (arithmetic) $\pm \mathrm{SD}$ (arithmetic). Vitamin A contents were expressed in terms of international units (IU) in both the fourth version of the tables ${ }^{11}$ and the pre-cooked food tables ${ }^{24}$, whereas it was in retinol equivalents (RE) in the fifth version ${ }^{10}$. For conversion of the value in IU to that in RE, $10 \mathrm{IU}$ was thought to be equivalent to $3 \mu \mathrm{g} \mathrm{RE}^{26}$.

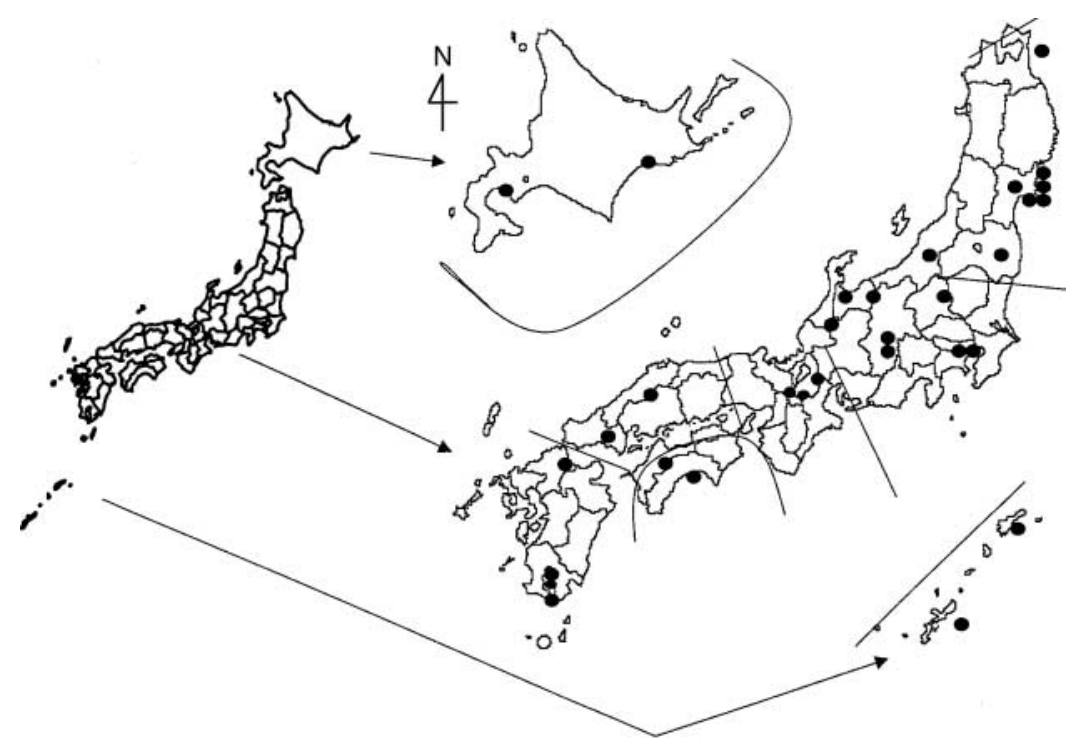

Fig. 1 Locations of survey sites, grouped by administrative region. Each solid circle indicates a survey site where food duplicate portion samples were collected 
Table 1 Recommended dietary allowances for Japanese women by age range

\begin{tabular}{|c|c|c|c|c|}
\hline \multirow[b]{2}{*}{ Nutrient (units day ${ }^{-1}$ ) } & \multicolumn{4}{|c|}{ Age range (years) } \\
\hline & $18-29$ & $30-49$ & $50-69$ & 70 and over \\
\hline Energy (kcal) & 2050 & 2000 & 1900 & 1700 \\
\hline Protein (g) & 55 & 55 & 55 & 55 \\
\hline Lipid (g) & $38-57$ & $38-57$ & $38-57$ & $38-57$ \\
\hline Dietary fibre (g) & $17-20.5$ & $17-20.5$ & $17-20.5$ & $17-20.5$ \\
\hline \multicolumn{5}{|l|}{ Minerals } \\
\hline $\mathrm{Ca}(\mathrm{mg})$ & 600 & 600 & 600 & 600 \\
\hline$P(\mathrm{mg})$ & 700 & 700 & 700 & 700 \\
\hline $\mathrm{Fe}(\mathrm{mg})$ & 12 & $12 \ddagger$ & $12 \ddagger$ & 10 \\
\hline $\mathrm{K}(\mathrm{mg})$ & 2000 & 2000 & 2000 & 2000 \\
\hline $\mathrm{NaCl}^{*}(\mathrm{~g})$ & $<10$ & $<10$ & $<10$ & $<10$ \\
\hline \multicolumn{5}{|l|}{ Vitamins } \\
\hline Vitamin A ( $\mu \mathrm{g}$ RE $\dagger)$ & $540-1500$ & $540-1500$ & $540-1500$ & $540-1500$ \\
\hline Vitamin $B_{1}(\mathrm{mg})$ & 0.8 & 0.8 & 0.8 & 0.8 \\
\hline Vitamin $B_{2}(\mathrm{mg})$ & 1.0 & 1.0 & 1.0 & 1.0 \\
\hline Vitamin $C^{2}(\mathrm{mg})$ & 100 & 100 & 100 & 100 \\
\hline Niacin (mg) & $13-30$ & $13-30$ & $13-30$ & $13-30$ \\
\hline
\end{tabular}

The sixth recommended daily allowances (RDAs) for women with moderate physical exercise ${ }^{26}$.

${ }^{*}$ Assuming that all $\mathrm{Na}$ is attributable to sodium chloride $(\mathrm{NaCl})$; the value is not an RDA but the recommended upper limit of acceptance.

† Retinol equivalent; $300 \mu \mathrm{g} R=1000 \mathrm{IU}$

$\ddagger 10 \mathrm{mg} \mathrm{day}^{-1}$ after the menopause.

Table 2 Intakes of macro- and micronutrients

\begin{tabular}{|c|c|c|c|c|c|}
\hline \multirow[b]{2}{*}{ Nutrient (units day ${ }^{-1}$ ) } & \multicolumn{2}{|c|}{$\begin{array}{l}\text { Intake (mean } \pm \text { standard deviation) } \\
\text { as estimated with }\end{array}$} & \multirow[b]{2}{*}{ Difference in mean $\dagger$} & \multirow[b]{2}{*}{$P$-value $\neq$} & \multirow[b]{2}{*}{$\%$ change§ } \\
\hline & Fourth version & Fifth version & & & \\
\hline Energy (kcal) & $1818 \pm 422$ & $1945 \pm 447$ & 127 & ** & 7.1 \\
\hline Protein $(\mathrm{g})$ & $67.0 \pm 18.4$ & $66.8 \pm 18.6$ & -0.2 & ** & -0.4 \\
\hline Carbohydrate (g) & $277 \pm 73$ & $306 \pm 79$ & 29 & ** & 10.4 \\
\hline Lipid (g) & $47.1 \pm 17.3$ & $47.9 \pm 18.3$ & 0.8 & ** & 1.6 \\
\hline Dietary fibre (g) & $13.0 \pm 6.0$ & $17.1 \pm 7.0$ & 4.1 & ** & 38.1 \\
\hline Water-soluble (g) & $2.58 \pm 1.50$ & $3.48 \pm 1.46$ & 0.90 & ** & 62.7 \\
\hline Water-insoluble (g) & $10 \pm 4.45$ & $12.15 \pm 5.05$ & 2.11 & ** & 25.6 \\
\hline \multicolumn{6}{|l|}{ Minerals } \\
\hline $\mathrm{Ca}(\mathrm{mg})$ & $600 \pm 249$ & $610 \pm 253$ & 10 & ** & 2.8 \\
\hline$P(m g)$ & $951 \pm 286$ & $1020 \pm 304$ & 69 & ** & 7.5 \\
\hline $\mathrm{Fe}(\mathrm{mg})$ & $10.0 \pm 3.2$ & $8.9 \pm 3.0$ & -1.1 & ** & -10.8 \\
\hline $\mathrm{K}(\mathrm{mg})$ & $2583 \pm 959$ & $2666 \pm 961$ & 83 & ** & 3.4 \\
\hline $\mathrm{NaCl} \mid(\mathrm{g})$ & $10.8 \pm 4.0$ & $10.5 \pm 3.8$ & -0.3 & ** & -0.6 \\
\hline \multicolumn{6}{|l|}{ Vitamins } \\
\hline Vitamin $\mathrm{A}(\mu \mathrm{g} \mathrm{RE} \|)$ & $830 \pm 826$ & $1066 \pm 852$ & 236 & ** & 40.0 \\
\hline Vitamin $B_{1}(\mathrm{mg})$ & $0.83 \pm 0.31$ & $0.80 \pm 0.32$ & -0.03 & ** & -3.3 \\
\hline Vitamin $B_{2}(\mathrm{mg})$ & $1.23 \pm 0.43$ & $1.21 \pm 0.44$ & -0.02 & ** & -0.9 \\
\hline Vitamin $C(\mathrm{mg})$ & $127 \pm 73.3$ & $126.2 \pm 71.0$ & -0.5 & NS & 1.4 \\
\hline Niacin $(\mathrm{mg})$ & $12.3 \pm 6.1$ & $13.7 \pm 7.6$ & 1.5 & $\star \star \star$ & 11.6 \\
\hline \multicolumn{6}{|l|}{ Fatty acids } \\
\hline Saturated (g) & $9.9 \pm 5.0$ & $12.4 \pm 6.1$ & 2.5 & ** & 34.0 \\
\hline Monounsaturated (g) & $12.7 \pm 5.9$ & $14.8 \pm 6.7$ & 2.0 & ** & 20.9 \\
\hline Polyunsaturated (g) & $10.4 \pm 4.8$ & $11.7 \pm 5.1$ & 1.3 & ** & 14.7 \\
\hline Cholesterol (mg) & $230 \pm 161$ & $281 \pm 161$ & 51.6 & ** & 73.2 \\
\hline
\end{tabular}

$\dagger$ The difference is calculated as the value obtained from the 5 th version minus the value obtained from the fourth version.

$\ddagger$ The statistical significance of the difference: ${ }^{\star \star}, P \leq 0.01 ;{ }^{*}, P \leq 0.05$; NS, $P>0.05$, as examined by Student's paired $t$-test $(n=783$ ).

$\S$ The average \% change for each item is shown; the percentage change - i.e. (the difference divided by the value obtained from the fourth version) $\times 100$ - was first calculated on an individual basis, and then the average of the percentages was calculated.

If Assuming that all $\mathrm{Na}$ is attributable to sodium chloride $(\mathrm{NaCl})$.

$\|$ Retinol equivalent; $300 \mu \mathrm{g} R=1000 \mathrm{IU}$.

All data were analysed using SPSS version 10 (SPSS Inc., Chicago, IL, USA). Student's paired $t$-test was employed for detection of a significant difference between the two estimates of nutrient intakes, one based on the fourth version of the tables and the other on the fifth. One-way analysis of variance and the multiple comparison test
(Tukey-Kramer) were employed to detect possible significant differences among means of various age groups. Nationally recommended dietary allowances (RDA) ${ }^{26}$ were employed for evaluation of the estimated intakes; the RDA values for adult non-pregnant and non-lactating women with moderate physical exercise are cited in Table 1. 


\section{Results}

Table-dependent changes in the estimates of macroand micronutrient intakes

The estimates of nutrient intakes based on the fourth and fifth version of the tables are summarised in Table 2, together with the statistical significance of the difference between the two estimates. Comparison shows that the estimations by use of the fifth version gave substantially higher values than that by the fourth version for some nutrient items. In calculating percentage changes, they were calculated first on an individual basis and then the average percentage change was determined based on the individual percentages. Therefore, the average percentage change thus obtained does not always agree with the percentage changes calculated from the means of the fourth and fifth version-based estimates.

Items with a $>10 \%$ change were identified: they were carbohydrate $(+10.4 \%)$, dietary fibre $(+38.1 \%)$, iron $(-10.8 \%)$, niacin $(11.6 \%)$, three types of fatty acids (i.e. saturated, monounsaturated and polyunsaturated; +14.7 to $+34.0 \%$ depending on type) and cholesterol $(+73.2 \%)$. Although it was less than $10 \%$, the change in energy intake estimates $(+7.1 \%)$ was considered also important, because energy intake is fundamental for health and life.

\section{Age dependency in the change}

Among the food items with $>10 \%$ changes, further analysis was made on energy, carbohydrate, fibre, iron and niacin. $\mathrm{NaCl}$ intake was considered in addition because of its implication in public nutrition, to be discussed later. In the case of vitamin A, the current estimates of intake were well in the range of RDA (Table 1) irrespective of the tables employed for estimation, and therefore the change in the estimation was thought to be less important. Fatty acids and cholesterol were not evaluated further, due to limitation in information as discussed later.

Comparison of the percentage changes among six age groups (Table 3) showed that the changes in intake estimation of energy, water-soluble dietary fibre, iron and niacin were rather uniform $(P>0.05)$ with no agedependent difference. In the case of carbohydrate, however, the change was more remarkable among older groups (e.g. $12.0 \%$ in $\geq 70$-year-old women) compared with the young group (e.g. $8.1 \%$ in the 20 - to 29 -year-old women). In the cases of water-soluble dietary fibre and iron, in contrast, the changes in the estimation (an increase in the case of fibre and a decrease for iron) were more remarkable in the younger women than in the older women. For $\mathrm{NaCl}$ intake estimation, the change was positive (indicating an increase in the estimation) in younger women and negative (i.e. a decrease) in the older women.

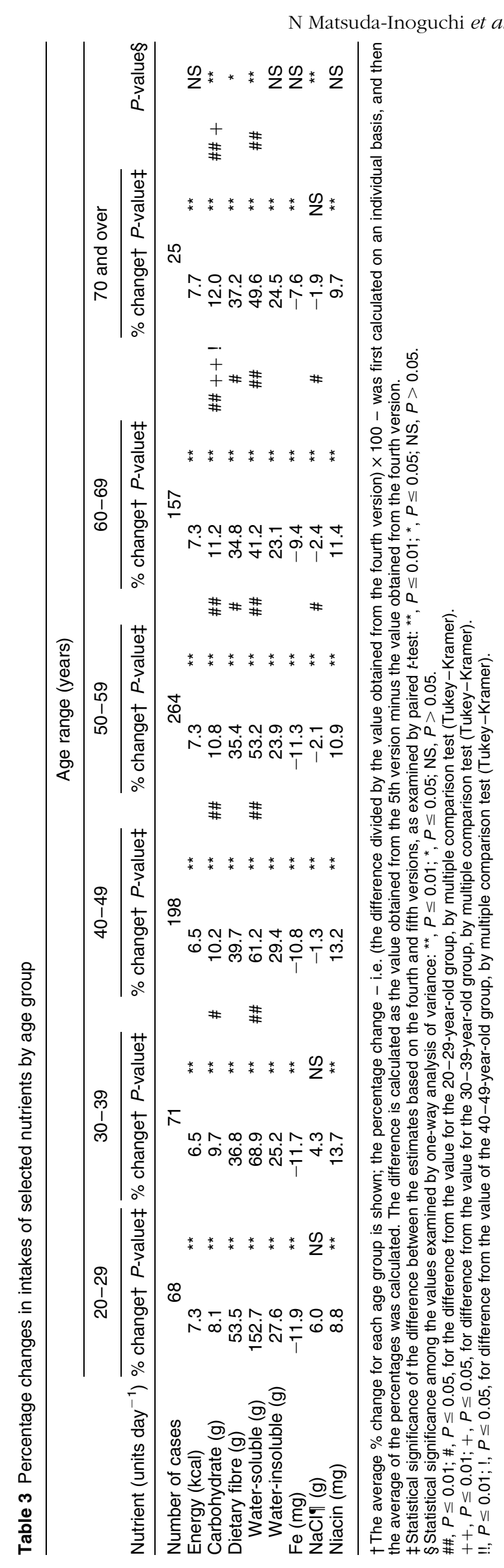




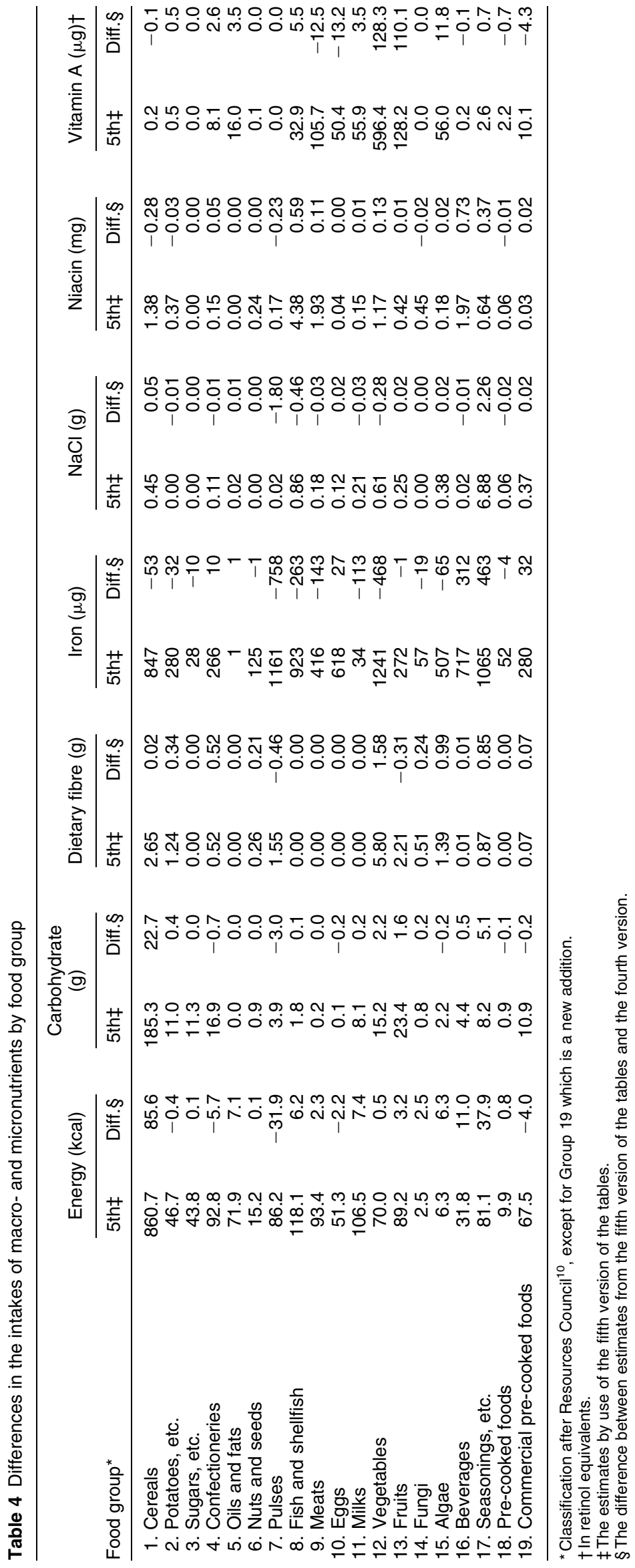




\section{Food groups that induced an increase or a decrease in estimations}

To identify the food groups that played major roles in inducing these differences, food items from each woman were classified into 19 groups in accordance with the 18 groups in the food composition tables ${ }^{10}$ together with a supplemental group (Group 19) for commercially available pre-cooked foods. The average (for women of all ages) estimates from the fifth version, the difference between the two estimates (i.e. the value from the fifth version minus the value from the fourth version) and the percentage change (the difference divided by the value from the fourth version in \%) of each food group, respectively, were calculated for energy, carbohydrate, dietary fibre (water-soluble and -insoluble), iron, $\mathrm{NaCl}$ and niacin (Table 4).

The calculation for energy showed (Table 4) that the majority of the difference, i.e. $85.6 \mathrm{kcal}$ out of $127 \mathrm{kcal}$ (or $67 \%$ ), was attributable to cereals. The same also applied to carbohydrate, as cereals were the major sources of carbohydrates. Comparison of the two composition tables, the fourth ${ }^{11}$ and the fifth versions ${ }^{10}$, made it clear that this was due to re-evaluation of the energy per unit weight of boiled rice in $11^{10,}$ reflection of a reduced estimation of the water content in boiled rice after shifts in the liking of people. The reduction of energy, iron and $\mathrm{NaCl}$ in pulses and the increase in seasonings were due to classification changes of miso paste (a fermentation product of soy beans, salt and rice (or wheat) ${ }^{27}$ ) from the pulses group in the fourth version ${ }^{11}$ to the seasoning group in the fifth version ${ }^{10}$. The increase in dietary fibre was primarily due to re-evaluation (an increase) of the water-insoluble fibre in some vegetables (e.g. pumpkin) in the fifth version ${ }^{10}$.

In the case of iron intake estimation, both the major sources and the food groups that induced the differences were various. Nevertheless, it is worthy to note that the major reduction came from a re-evaluation of iron losses from vegetables during the cooking process. For example, iron in spinach after boiling was revised from $2.0 \mathrm{mg} / 100 \mathrm{~g}$ in the fourth version ${ }^{11}$ to $0.9 \mathrm{mg} / 100 \mathrm{~g}$ in the fifth version ${ }^{10}$. The increase in niacin was mostly due to increased evaluation of the niacin content in some types of sea fish and several types of soft drink such as Japanese green tea ${ }^{10}$. With regard to vitamin $\mathrm{A}$, the increase was attributable to re-evaluation of the content in plant foods such as pumpkin, spinach and mandarins ${ }^{10}$.

\section{Discussion}

The present analysis makes it clear that revision of the food composition tables from the fourth to the fifth version induced substantial increases in the estimated intakes of energy, carbohydrate and vitamin A, and a decrease in the estimation of iron intake. The observation is in close agreement with the results of a previous study on girl students ${ }^{14}$, suggesting that the applicability of the conclusion is not limited to young women, but can be extended to adult Japanese women in general. Additional findings from the present analysis are increases in the estimates of dietary fibre, niacin, fatty acids and cholesterol, possibly due to the 10 -fold increase in the number of women studied, from 71 cases in the previous study $^{14}$ to 783 cases in the present analysis.

The meaning of these observations should be evaluated at least from two viewpoints. One is the evaluation with reference to the $\mathrm{RDA}^{25}$ as listed in Table 1. The comparison on energy suggests that the estimates (1818 or $1945 \mathrm{kcal} \mathrm{day}^{-1}$; Table 2) are most probably not in excess of (although very close to) the RDA for energy intake (1700-2050 kcal day ${ }^{-1}$; Table 1), irrespective of the version of the food composition tables. Nevertheless, elevated risk of obesity-associated adverse health effects such as diabetes, hyperlipidaemia and hypertension has been observed for Japanese populations at an even lower grade of obesity than for American and European populations ${ }^{28}$. Thus, more attention is necessary for the prevention of excess weight gain. A simple calculation suggests that an excess intake of $127 \mathrm{kcal} \mathrm{day}^{-1}$ (Table 2) may result in weight gain of $15.88 \mathrm{~g} \mathrm{day}^{-1}\left[=\left(127 \mathrm{kcal} \mathrm{day}^{-1}\right) /(8 \mathrm{kcal} / \mathrm{g}\right.$ fat $\left.)\right]$ or about $5.8 \mathrm{~kg}\left(=15.88 \mathrm{~g} \mathrm{day}^{-1} \times 365\right.$ days $)$ per year, assuming that the energy is converted to fat and stored in the body. Thus, an accurate estimation of total energy intake is apparently desirable.

Intakes of vitamin A and niacin (Table 2) are either sufficient or barely so when compared with the corresponding RDA values (Table 1). In the case of iron intake, however, the $10 \%$ reduction in estimated intake may need attention because the current level of intake, $8.9 \mathrm{mg} \mathrm{day}^{-1}$ (the estimation based on the fifth version; Table 2), does not meet the recommendation (12 mg day $^{-1}$; Table 1). It was further made clear (Table 3) through the present analysis that the effects of reevaluation of iron intake were greater in young women than in older women. Insufficient iron intake especially among young women has been a problem elsewhere in the world as well as in Japan ${ }^{14,18,19,29-34}$. In this connection, it has been noticed that estimations based on food composition tables tend to give a larger iron intake than the results of inductively coupled plasmamass spectrometry analysis ${ }^{8}$ of food duplicate portions, in support of the present observation.

In contrast, results for the estimation of $\mathrm{NaCl}$ intake by use of the two versions agreed well with each other (Table 2). It was previously observed that the estimates of salt intake based on the tables agree well with the results of instrumental analysis ${ }^{7}$. Nevertheless, $\mathrm{NaCl}$ intake by young women (and not of older women) as estimated by use of the fifth version of the tables was greater by $6 \%$ than the estimate by the fourth version of 
the tables (Table 3). The observation suggests the possibility that the $\mathrm{NaCl}$ intake of younger people has been underestimated for years, which is apparently not favourable for the prevention of $\mathrm{NaCl}$-induced hypertension in later life.

With regard to fatty acids, the ratio of S:M:P $=3: 4: 3$ has been recommended for intakes of saturated (S), monounsaturated $(\mathrm{M})$ and polyunsaturated $(\mathrm{P})$ fatty acids, but no numerical values were given ${ }^{26}$ for quantitative evaluation. Thus, no further evaluation was made on fatty acids in the present study, as available information on recommended intake is still insufficient. It should be added that the current S:M:P ratio of 10:13:10 or 12:15:12 (Table 2) is close to the recommendation described above $^{26}$. With regard to cholesterol, a reduction in intake to less than $300 \mathrm{mg} \mathrm{day}^{-1}$ is recommended for those with a tendency to hypercholesterolaemia ${ }^{26}$, but this recommendation may not necessarily be applicable to general healthy populations as was the survey population of the present study.

The extent of the effects of the revision should also be evaluated from a chronological viewpoint. The last five annual (i.e. from 1996 to 2000) reports from the National Nutritional Survey in Japan gave nutrient intake values for women separately from the values for men ${ }^{13}$. The estimations were based on the fourth version of the food composition tables. Linear regression analyses of the reported values, taking the survey years from 1996 to 2000

a)

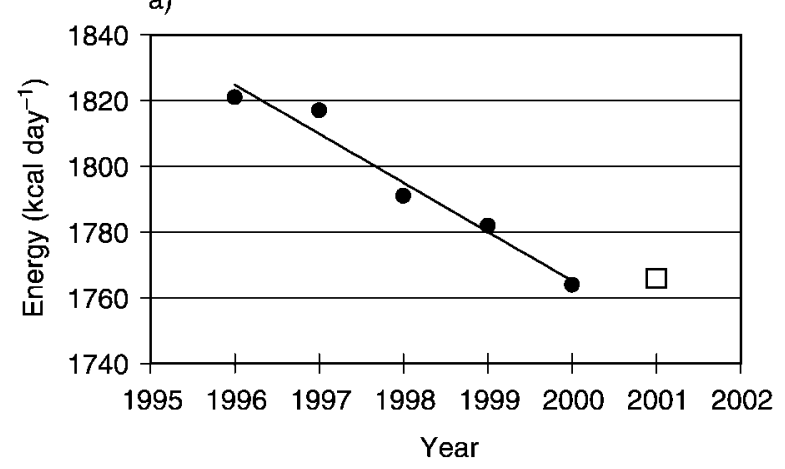

c)

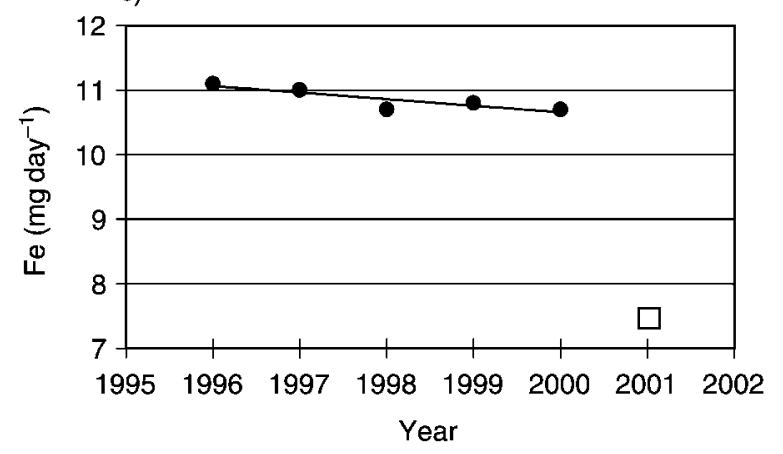

(Fig. 2) on the horizontal axis and the nutrient intakes on the vertical axis, gives:

$Y_{1}=31565-14.9 X(r=-0.981, \quad P<0.01)$ for energy,

$Y_{2}=4644-2.2 X(r=-0.996, P<0.01)$ for carbohydrate,

$Y_{3}=260.7-0.10 X(r=-0.870, \quad P>0.10)$ for iron, and

$Y_{4}=351.7-0.17 X(r=-0.981, \quad P<0.01)$ for $\mathrm{NaCl}$,

where $X$ is the year of the survey, and $Y_{1}, Y_{2}, Y_{3}$ and $Y_{4}$ are daily intake of energy ( $\mathrm{kcal} \mathrm{day}^{-1}$ ), carbohydrate $\left(\mathrm{g} \mathrm{day}^{-1}\right)$, iron $\left(\mathrm{mg} \mathrm{day}^{-1}\right)$ and $\mathrm{NaCl}\left(\mathrm{g}\right.$ day $\left.{ }^{-1}\right)$, respectively. Division of the fifth version minus the fourth version difference in the estimates (Table 2) by the corresponding slope of the regression line gives -8.5 , $-4.8,10.9$ and 1.8 years for the four items, respectively, as the time in years necessary to induce the changes based on the current chronological trends in nutrient intakes; the plus and minus signs indicate the future and the past, respectively. The longest time is about 11 years for iron followed by -9 years for energy, which suggests that revision of the food composition tables may induce a substantially large artificial gap in the time-dependent trends of energy and iron (as the major source of energy is carbohydrate, the implication of the values for energy and carbohydrate should be the same). The estimates for the year $2001^{13}$, which were based on the fifth version of the
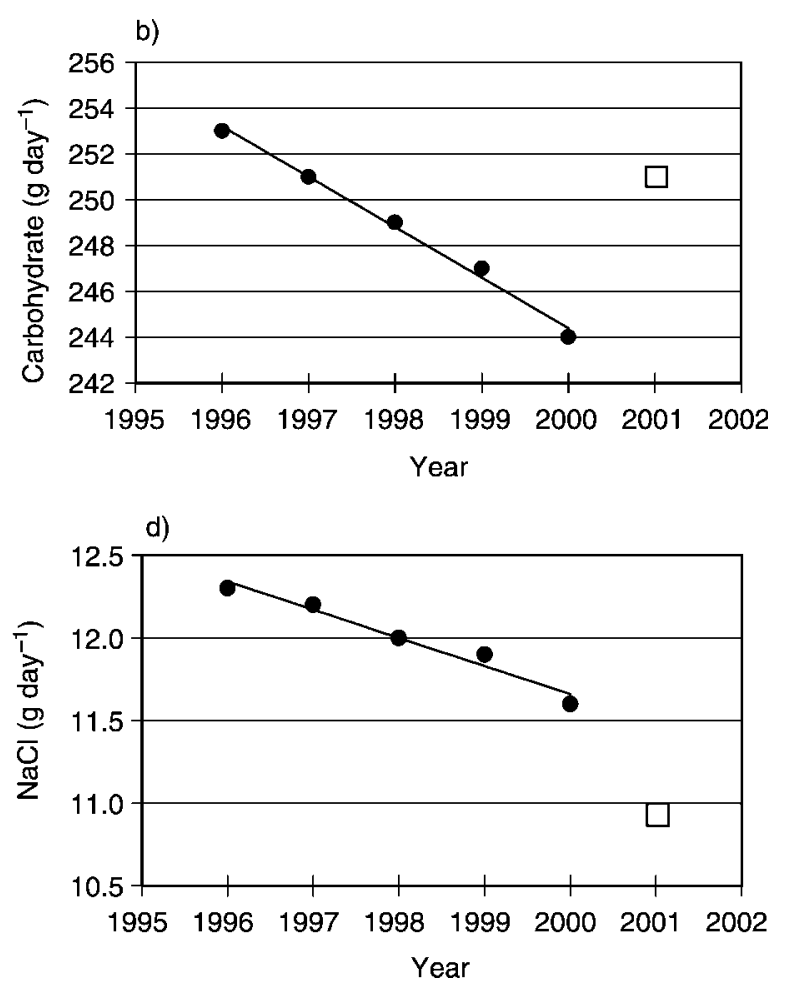

Fig. 2 Chronological trends observed in the Japanese National Nutritional Survey for (a) energy, (b) carbohydrate, (c) iron and (d) NaCl. Solid circles show the values for the years 1996 to 2000, which were based on the fourth version of the tables, and open squares show the values for the year 2001 , which were based on the fifth version of the tables ${ }^{13}$. The line is a calculated regression line based on the data shown by the five solid circles 
tables $^{10}$, are also plotted in Fig. 2 to show the deviation from the continuity observed in the National Nutritional Survey results. Whereas food composition tables should be revised to keep up with the latest developments in science $^{1}$, it is also important to pay attention to maintain continuity in the evaluation of time trends.

\section{Conclusions}

The revision of the food composition tables from the fourth version to the fifth version induced substantial increases in intake estimation for energy, carbohydrate, dietary fibre, vitamin A and niacin, and decreases in iron. The changes were age-dependent, such that the increase in carbohydrate intake estimation was more marked in older women, whereas the increase in intake of dietary fibre and the decrease in intake of iron were more evident in young women. The importance of continuity in food intake evaluation was stressed in chronological analysis.

\section{Acknowledgements}

This work was supported in part by the 1999 Kyoto City Research Fund for Promotion of Health of Citizens to S.S., T.W. and M.I., and by sponsorship by the Ministry of Education, Science, Sports and Culture, the Government of Japan. The authors are grateful to Miss F Ohashi of Kyoto Industrial Health Association for her skilful PC operation.

\section{References}

1 Dwyer JT. Future directions in food composition studies. Journal of Nutrition 1994; 124(Suppl. 9): 1783S-8S.

2 Clark AJ, Mossholder S. Sodium and potassium intake measurements; dietary methodology problems. American Journal of Clinical Nutrition 1986; 43: 470-6.

3 Knuiman JT, Rasanen L, Ahola M, West CE, van den Snoek L. The relative validity of reports of food intake of Dutch and Finnish boys aged 8 and 9 years. Journal of the American Dietetic Association 1987; 87: 303-7.

4 Nagata Y, Suzue R. Comparison of young women's salt intake between Japan and England: consideration on different measurement methods in national nutrition surveys. Journal of Nutritional Science and Vitaminology 1996; 42: 19-26.

5 Tsubono Y, Sasaki S, Kobayashi M, Akabane M, Tsugane S. Food composition and empirical weight methods in predicting nutrient intakes from food frequency questionnaire. Annals of Epidemiology 2001; 11: 213-8.

6 Sasaki S, Matsumura Y, Ishihara J, Tsugane S. Validity of a self-administered food frequency questionnaire used in the 5-year follow-up survey of the JPHC Study Cohort I to assess dietary fiber intake; comparison with dietary records. Journal of Epidemiology 2003; 13(Suppl. 1): S106-14.

7 Shimbo S, Zhang Z-W, Miyake K, Watanabe T, Nakatsuka H, Matsuda-Inoguchi $\mathrm{N}$, et al. Estimates of mineral intakes using food composition tables vs measures by inductively-coupled plasma mass spectrometry: Part 2. Sodium, potassium, magnesium, copper and zinc. European Journal of Clinical Nutrition 1999; 53: 233-8.
8 Zhang Z-W, Shimbo S, Miyake K, Watanabe T, Nakatsuka H, Matsuda-Inoguchi $\mathrm{N}$, et al. Estimates of mineral intakes using food composition tables vs measures by inductively-coupled plasma mass spectrometry: Part 1. Calcium, phosphorus and iron. European Journal of Clinical Nutrition 1999; 53: 226-32.

9 Kim E-S, Ko Y-S, Kim J, Matsuda-Inoguchi N, Nakatsuka H, Watanabe $\mathrm{T}$, et al. Food composition table-based estimation of energy and major nutrient intake in comparison with chemical analysis: a validation study in Korea. Toboku Journal of Experimental Medicine 2003; 200: 7-15.

10 Resource Council, Science and Technology Agency, the Government of Japan. Standard Tables of Food Composition in Japan, 5th revised version. Tokyo: Ministry of Finance Printing Bureau, 2000 [in Japanese with English translation].

11 Resource Council, Science and Technology Agency, the Government of Japan. Standard Tables of Food Composition in Japan, 4th revised version. Tokyo: Ministry of Finance Printing Bureau, 1982 [in Japanese with English translation].

12 Ministry of Health and Welfare, the Government of Japan. Review on Public Nutrition in Japan in 1955 to 1988. Tokyo: Dai-ichi Shuppan Press, 2000 [in Japanese].

13 Ministry of Health and Welfare, the Government of Japan. National Nutritional Survey in Japan, 1989-2001 [annual reports]. Tokyo: Dai-ichi Shuppan Press, 1991-2003 [in Japanese].

14 Matsuda-Inoguchi N, Nakatsuka H, Watanabe T, Shimbo S, Higashikawa K, Ikeda M. Estimation of nutrient intake by the new version of Japanese food composition tables in comparison with that by the previous version. Toboku Journal of Experimental Medicine 2001; 194: 229-39.

15 Ikeda J, Asano H, Nagata H. Dietary life of female college students (Part 1). Survey on nutrition awareness and their mode of living affecting their nutrient intake [in Japanese with English abstract]. Japanese Journal of Nutrition 1983; 41: $103-16$.

16 Shiraki M, Iwasaki N. Effects of a habit of skipping meals on dietary life of college students [in Japanese with English abstract]. Japanese Journal of Nutrition 1986; 44: 257-65.

17 Someya R, Negishi Y, Mizuno K, Muto S. Dietary life of female college students [in Japanese with English abstract]. Japanese Journal of Nutrition 1989; 47: 251-8.

18 Cai MQ, Yan WY. Study on iron nutritional status in adolescence. Biomedical and Environmental Sciences 1990; 3: $113-9$.

19 Hendricks KM, Herbold NH. Diet, activity, and other healthrelated behaviors in college women. Nutrition Reviews 1998; 56: $65-75$.

20 Watanabe T, Zhang Z-W, Moon C-S, Shimbo S, Nakatsuka H, Matsuda-Inoguchi N, et al. Cadmium exposure of women in general populations in Japan during 1991-1997 compared with 1977-1981. International Archives of Occupational and Environmental Health 2000; 73: 26-34.

21 World Health Organization (WHO). Guidelines for the Study of Dietary Intakes of Chemical Contaminants. WHO Offset Publication No. 87. Geneva: WHO, 1985.

22 Resource Council, Science and Technology Agency, the Government of Japan. Standard Tables of Food Composition in Japan; Dietary Fibers. Tokyo: Ministry of Finance Printing Bureau, 1992 [in Japanese with English translation].

23 Resource Council, Science and Technology Agency, the Government of Japan. Standard Tables of Food Composition in Japan; Fatty Acids, Cholesterol and Vitamin E. Tokyo: Ministry of Finance Printing Bureau, 1989 [in Japanese with English translation].

24 Kagawa Y. Food Composition Tables for Commercial Precooked Food. Tokyo: Kagawa University of Nutrition Press, 1995 [in Japanese].

25 Shimbo S, Hayase A, Murakami M, Hatai I, Higashikawa K, 
Moon C-S, et al. Use of a food composition database to estimate daily dietary intake of nutrient or trace elements in Japan, with reference to its limitation. Food Additives and Contaminants 1996; 13: 775-86.

26 Ministry of Health and Welfare, the Government of Japan. Recommended Dietary Allowances, 6th version. Tokyo: Dai-ichi Shuppan Press, 1999 [in Japanese].

27 Watanabe T, Miyasaka M, Koizumi A, Ikeda M. Regional difference in sodium chloride content in home-made and store-bought preparations of miso paste. Toboku Journal of Experimental Medicine 1982; 137: 305-13.

28 Obesity Criteria Committee, Japan Society for Study on Obesity. New concept of obesity and diagnostic criteria [in Japanese]. Journal of the Japanese Society for the Study of Obesity 2000; 6: 18-28.

29 Shimbo S, Imai Y, Tominaga N, Gotoh T, Yokota M, Inoguchi $\mathrm{N}$, et al. Insufficient calcium and iron intakes among general female population in Japan, with special reference to interregional differences. Journal of Trace Elements in Medicine and Biology 1996; 10: 133-8.

30 Shimbo S, Moon C-S, Zhang Z-W, Watanabe T, Noor Hassim I, Romzi MA, et al. Nutritional evaluation of working Malay women in Kuala Lumpur as studied by total food duplicate method. Toboku Journal of Experimental Medicine 1996; 180: 99-114.

31 Shimbo S, Moon C-S, Zhang Z-W, Watanabe T, Guo LL, Ma W-C, et al. Nutritional evaluation of Chinese working women in the city of Tainan, Taiwan. Toboku Journal of Experimental Medicine 1997; 181: 339-52.

32 Moon C-M, Zhang Z-W, Imai M, Shimbo S, Watanabe T, Moon D-H, et al. Nutritional status of women in urban and rural areas in Korea as assayed by total food duplicate method. Tohoku Journal of Experimental Medicine 1997; 181: $245-65$.

33 Nakatsuka H, Zhang Z-W, Agetano MG, Subida RD, Inouguchi $\mathrm{N}$, Watanabe $\mathrm{T}$, et al. Total food duplicate study on nutrient intake of working women in Manila, the Philippines. Toboku Journal of Experimental Medicine 1998; 184: 189-205.

34 Matsuda-Inoguchi N, Shimbo S, Zhang Z-W, Srianujata S, Banjong $\mathrm{O}$, Chitchumroonchokchai $\mathrm{C}$, et al. Nutrient intake of working women in Bangkok, Thailand, as studied by total food duplicate method. European Journal of Clinical Nutrition 2000; 54: 187-94. 